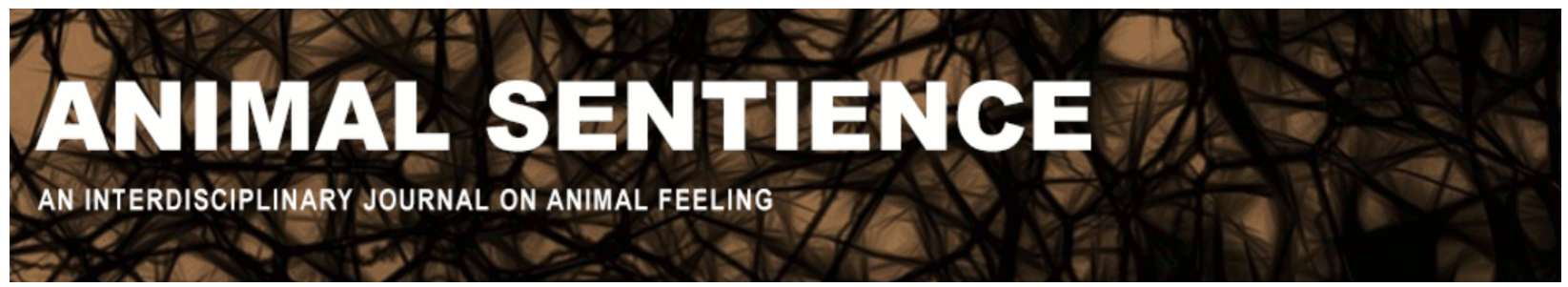

Andrade, Michaella P. and Santos, Charles Morphy D. (2019) On neglected taxa: Protostomes and the evolution of myelination. Animal Sentience 21(18) DOI: $10.51291 / 2377-7478.1512$

Date of submission: 2019-08-23

Date of acceptance: 2019-12-12 (c)

This article has appeared in the journal Animal Sentience, a peer-reviewed journal on animal cognition and feeling. It has been made open access, free for all, by WellBeing International and deposited in the WBI Studies Repository. For more information, please contact

wbisr-info@wellbeingintl.org.

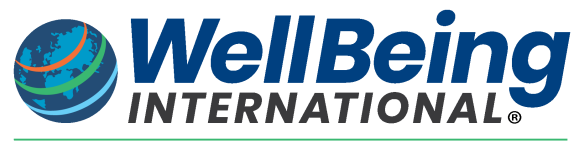

SOLUTIONS FOR PEOPLE, ANIMALS AND ENVIRONMENT 


\title{
On neglected taxa: Protostomes and the evolution of myelination
}

Commentary on Sneddon et al. on Sentience Denial

\author{
Michaella P. Andrade \& Charles Morphy D. Santos \\ Universidade Federal do ABC - UFABC, Brazil
}

\begin{abstract}
Understanding the evolution of nervous and sensory systems in animals is key to understanding the distribution of animal sentience. However, the use of model organisms mostly vertebrates, and especially mammals - often biases comparative analyses. Sneddon et al. $(2018 \mathrm{a}, \mathrm{b})$ point out that using nonhuman animals as models helps us better understand the multifaceted aspects of animal pain and sentience. Several concerns need to be considered in dealing with model organisms. Here we discuss how models that are unrepresentative phylogenetically influence hypotheses about the evolution of the myelination in animals. Greater effort is needed to escape "vertebrate-centrism" in evolutionary research.
\end{abstract}

Keywords: Deuterostomia, Metazoa, phylogeny, Prostostomia, taxon sampling

Michaella P. Andrade is a Master's student in the Graduate Program in Evolution and Diversity, Federal University of $A B C$ (UFABC), studying the evolution and phylogenetic distribution of animal sentience in Eumetazoa via evolutionary and comparative biology. Website

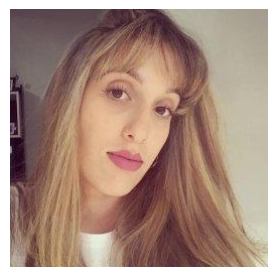

Charles Morphy D. Santos is Associate Professor of Comparative and Evolutionary Biology, Federal University of $A B C$ (UFABC), Brazil, with main research interests in animal evolution, especially systematic, insect, and related group biogeography; epistemology; philosophy of science; and science teaching. Website

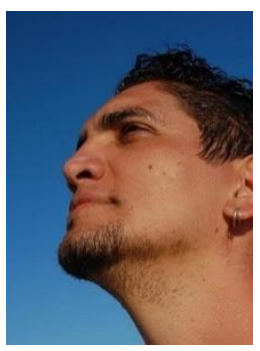

The evolution of sensory capacities dates back $c a$. 650 Million years, from the origin of mechanisms that capture environmental stimuli and generate sophisticated responses (Edgecombe et al., 2011). These capacities are linked to evolutionary novelties at different levels: emergence of bilateral symmetry, centralization of the nervous system, cephalization, and the origin of complex neuronal communication (Nave \& Werner, 2014; Liebeskind et al., 2017).

Studies with living species illuminate our understanding of the distribution of nervous and sensory systems in Metazoa. One of the interesting findings related to the evolution of the nervous system is the presence of small layers covering nerve fibers, the myelin sheaths,

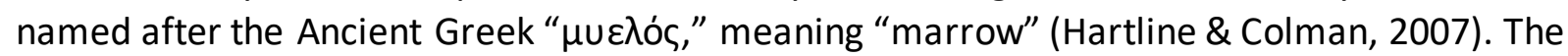
myelin sheath corresponds to a lipid-rich multilamellar layer that surrounds relatively large nerve fibers (except for type $\mathrm{C}$ fibers). It facilitates nerve impulses through the propagation of faster saltatory action potentials, with lower metabolic costs (Davis et al., 1999; Hartline \& Colman, 2007; Nave \& Werner, 2014; Castelfranco \& Hartline, 2015, 2016).

Myelination is well-known in deuterostomes, especially vertebrates, because of extensive studies with these animals, most of them focused on medical implications: 
demyelinating diseases affect the central nervous system and cause serious health problems, such as multiple sclerosis in human patients (Nakahara, 2012). Nonetheless, new research based on scanning electron microscopy has revealed the presence of myelin sheaths in different groups of protostomes. These structures are morphologically and functionally similar to those in deuterostomes, although the ecological issues and selective pressures involved in their evolution remain open (Hartline \& Colman, 2007; Nave \& Werner, 2014).

In protostomes, myelination has been identified in Crustacea - the crayfish Procambarus clarkai (Girard); the crab Cancer irroratus (Say); the shrimp Palaemonetes vulgaris (Say); the copepods Undinula vulgaris (Dana), Neocalanus gracilis (Dana), and Euchaeta rimana (Bradford); and Annelida - the earthworms Eisenia fetida (Savigny); Lumbricus terrestris (Linnaeus); Lumbricus variegatus (Müller); and Branchiura sowerbyi (Beddard) (Schweigreiter et al., 2006; Hartline, 2008). The phylogenetic pattern regarding the evolution of myelin sheaths in Metazoa generally accords with the topology in Figure 1.

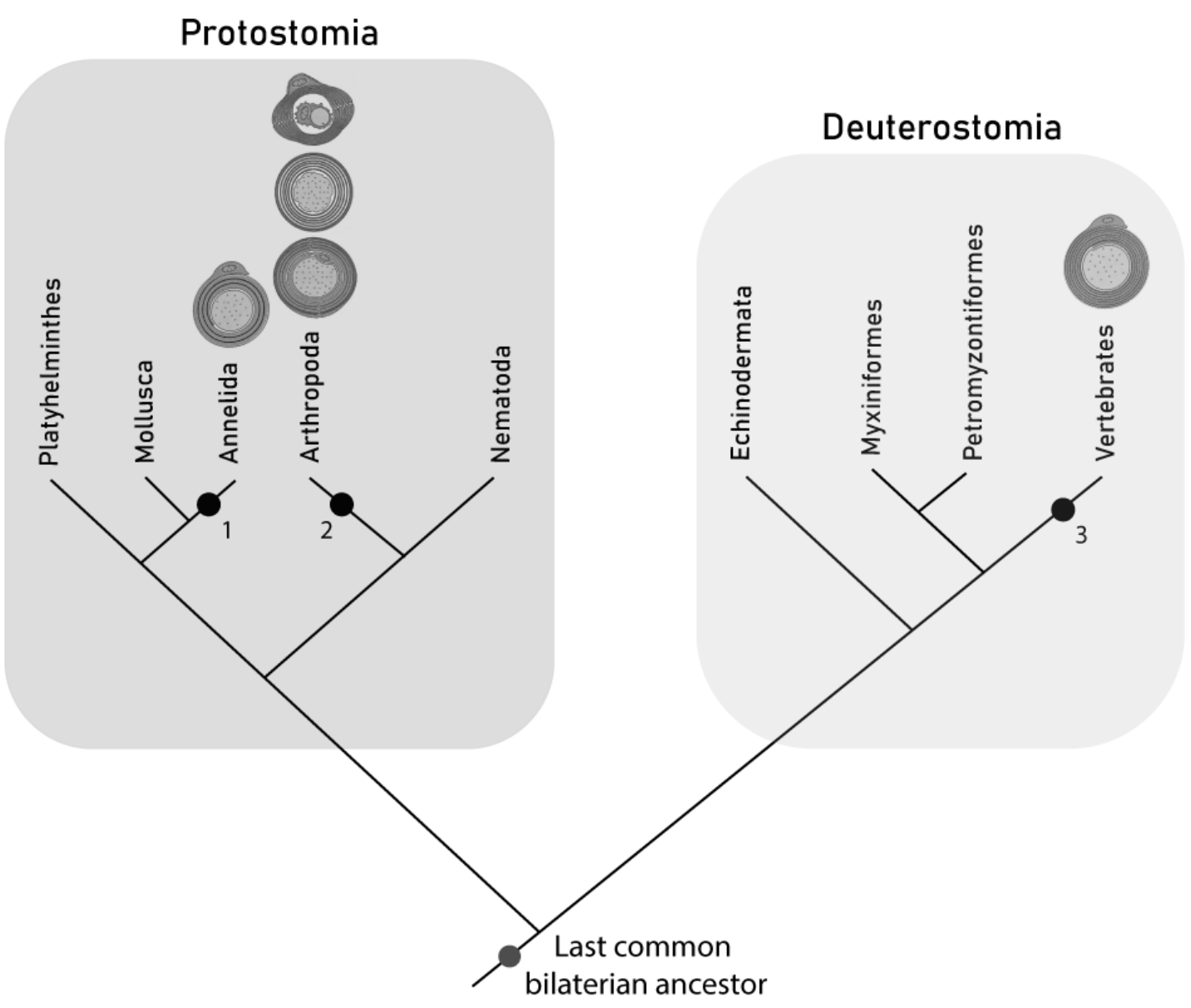

Figure 1. Condensed phylogenetic tree of Bilateria, showing the presence of myelination in (1) Annelida, (2) Arthropoda (Crustacea), and (3) Vertebrates. Modified from Hamamoto \& Simone (2003), Ashley et al. (2007), Hartline (2008), and Smith \& Lewin (2009).

Myelination has not yet been observed in other large protostomes clades such as Nematoda, Mollusca, and Platyhelminthes, nor in the deuterostome Echinodermata (Schweigreitter, 2006; Boullerne, 2016). Although Gould et al. (2008) recognize specific biochemical properties in the vertebrate myelin sheath (e.g., presence of MBP, MPZ, PMP22 genes), Wilson \& Hartline 
(2011) indicate that myelin in Oligochaeta, some groups of Crustacea (but not Copepoda), and vertebrates are derived from Schwann glia cells and oligodendrocytes. It is possible that myelination was not present in the last common ancestor of Protostomia and Deuterostomia; thus, the emergence of the myelin sheath in vertebrates may be convergent with the distinct myelin sheath present in the protostomes clades mentioned above. Further research using different animal models is necessary to better understand the subject. In fact, here lies an important issue regarding evolutionary studies in general, especially those based on phylogenetic and comparative reasoning.

The use of model organisms in comparative biology facilitates the construction of evolutionary scenarios (Hedges, 2002; Collins et al., 2005), including the multiple paths toward the evolution of myelination. Despite their general usefulness, model organisms are obviously limited concerning morphological and taxonomic sampling. This sort of bias is a problem especially in widescale phylogenetic and comparative studies. Briefly: using a single species of a group as the representative of the entire clade can yield conflicting results when compared to other data sets. A Bauplan (or ground plan) is a set of morphological attributes comm on to many members of a clade (Valentine, 2004), but caution is necessary when considering a certain species as representative of the body plan of a large clade - e.g., the zebrafish Danio rerio (Hamilton-Buchanan) representing the whole Actinopterygii (Sneddon et al., 2018a,b). Although the practice is frequent in molecular research (Lavrov, 2007), questions remain, such as "which model organism truly represents a large clade?" or "what is the impact on understanding evolution when only a small amount of diversity is available for analysis?" Concerning the main topic of this commentary, how much of our view of the evolution of sensory and nervous systems and myelination is impaired by taxon sampling limitations?

Smith \& Lewin (2009) and Sneddon (2017) have reported the absence of myelin sheaths in protostome nerve fibers. The relatively narrow sampling of the model organisms used in the studies biased both statements. Smith \& Lewin (2009) reviewed the phylogenetic evolution of nociceptors and discussed the absence of myelination in Annelida and Arthropoda based on the analysis of one model species for each clade, Hirudo medicinalis (Annelida) and Drosophila melanogaster (Arthropoda). Similarly, Sneddon (2017) addresses the comparative physiology of nociception and pain in animals using the same two model organisms for annelids and arthropods, although the article briefly discusses the limitations of choosing these species. The biological variability within Lophotrochozoa and Ecdysozoa is widely known: together, they account for more than 1.2 million species (Grimaldi \& Engel, 2005). In this sense, without considering a larger sample within the taxon, the hypothesis about the absence of myelin sheaths in protostomes lacks robustness. It is not that we should disregard the studies in the field based on the limited number of species or model organisms; they have pioneered comparative analysis on the physiology and evolution of nervous systems in Metazoa. What we argue for is the need for researchers to be aware that our hypotheses are necessarily limited when taxonomic sampling is small.

Taxon sampling is a determinant issue in phylogenetic and evolutionary studies since biased, incomplete, or improper sampling could often result in misleading evolutionary scenarios (Heath et al., 2008; Plazzi et al., 2010). It is really difficult to overcome taxon sampling limitations, especially in large-scale studies, but generalist hypotheses based on poor evidence may hamper future advances in evolutionary studies. According to Proctor et al. (2013), research related to sensory perception (e.g., sentience) in animals is largely focused on mammals for various reasons: the ease of using mammal species in comparative studies, the relatively small number of existing mammal species, and even an innate human tendency 
to concentrate our scientific inquiries on animals phylogenetically closer to the Homo sapiens. In this sense, the analysis of Sneddon et al. $(2018 a, b)$, indicating the presence of pain and sentience in fishes, is an interesting starting point for considering a much larger taxonomic range in studies of animal sensory perception.

Fortunately, in recent years, researchers have been making efforts also to deepen the understanding of the evolution of nervous systems in protostomes. A brief survey of the recent literature reveals an increasing number of studies describing the presence of myelination in protostomes (e.g., Schweigreitter, 2006; Hartline \& Colman, 2007; Castelfranco \& Hartline, 2015, 2016; De Bellard, 2016; Buskey et al., 2017; Liebeskind et al., 2017) and in clades outside Mammalia, such as fishes (Sneddon, 2017; Sneddon et al., 2018a,b).

Reinforcing Proctor et al.'s (2013) prospects, it seems clear that comparative studies of physiological structures related to nervous systems, such as the myelin sheath, remain poorly explored in clades unrelated to vertebrates. Much more than "mammalo-centric," the area is founded on a "vertebra-centric" paradigm, with research on sensory systems extensively focused on vertebrates even in broad trait analyses, often ignoring fundamental attributes also present in bilateral taxa unrelated to vertebrates.

Although studies have clarified issues related to nervous system differentiation in Metazoa, and the distribution of nociceptors and attributes related to nociception and pain (such as myelinated nerve fibers), the debate about sentience and awareness in animals remains inconclusive (Smith \& Lewin, 2009; Andrews, 2011; Crook, 2013; Teles, 2016). In this context, understanding the evolution of characters such as the myelin sheath is fundamental to understanding the origin of perception and sensory modulation along with mechanisms of pain and nociception within different animal groups (Elwood, 2011).

Looking at the limitations of taxon sampling in comparative research, questions remain open: will using model organisms assigned to large clades continue to be significant in evolutionary studies? given the extraordinary animal biodiversity in the last 700 million years, would choosing a model species for large clades (such as Annelida or Arthropoda) really help us understand the evolution of nervous system-related characters in Metazoa? Research on these topics should take into account a perspective much broader than the "vertebro-centric" one. Advances in protostome research are the sine qua non for a better understanding of the evolution of nervous, sensory, and sentient animal systems.

Acknowledgments: This work was supported by the Coordenação de Aperfeicoamento de Pessoal de Nível Superior, Brazil (CAPES) - Finance Code 001, CNPq [305630/2016-4] and FAPESP [2017/11768-8]. The authors would like to thank Daubian Santos, Fabio Mesquita do Nascimento, and Marcela Brasil for suggestions and comments on an earlier version of the manuscript.

\section{References}

Andrews, P. R. (2011). Laboratory invertebrates: only spineless, or spineless and painless? ILAR Journal, 52, 121-125.

Ashley, P. J., Sneddon, L. U. \& McCrohan, C. R. (2007). Nociception in fish: stimulus-response properties of receptors on the head of trout Oncorhynchus mykiss. Brain Research, 1166, 47-54.

Boullerne, A. I. (2016). The history of myelin. Experimental Neurology, 283, 431-445. 
Buskey, E. J., Strickler J. R., Bradley C. J., Hartline, D. K. \& Lenz, P. H. (2017). Escapes in copepods: comparison between myelinate and amyelinate species. Journal of Experimental Biology, 220, 754-758.

Castelfranco, A. M. \& Hartline, D. K. (2015). The evolution of vertebrate and invertebrate myelin: a theoretical computational study. Journal of Computational Neuroscience, 38, 521-538.

Castelfranco, A. M. \& Hartline, D. K. (2016). Evolution of rapid nerve conduction. Brain Research, 1641, 11-33.

Collins, A. G., Cartwright P., McFadden, C. S. \& Schierwater, B. (2005). Phylogenetic context and basal metazoan model systems. Integrative and Comparative Biology, 45, 585-594.

Crook, R. A. (2013). The welfare of invertebrate animals in research: can science's next generation improve their lot. Journal of Postdoctoral Research, 1, 1-20.

Davis, A. D., Weatherby, T. M., Hartline, D. K. \& Lenz, P. H. (1999). Myelin-like sheaths in copepod axons. Nature, 398, 571.

De Bellard, M. E. (2016). Myelin in cartilaginous fish. Brain Research, 1641, 34-42.

Edgecombe, G. D., Gonzalo, G., Casey W. D., Hejnol A., Kristensen, R. M., Neves, R. C., Rouse, G. W., Worsaae, K. \& Sørensen, M. V. (2011). Higher-level metazoan relationships: recent progress and remaining questions. Organisms Diversity \& Evolution, 11, 151-172.

Gould, R. M., Oakley, T., Goldstone, J. V., Dugas, J. C., Brady, S. T. \& Gow, A. (2008). Myelin sheaths are formed with proteins that originated in vertebrate lineages. Neuron Glia Biology, 4, 137-152.

Grimaldi, D. \& Engel, M. S. (2005). Evolution of the insects. Cambridge University Press.

Hamamoto, D. T. \& Simone, D. A. (2003). Characterization of cutaneous primary afferent fibers excited by acetic acid in a model of nociception in frogs. Journal of Neurophysiology, 90, 566-577.

Hartline, D. K. \& Colman, D. R. (2007). Rapid conduction and the evolution of giant axons and myelinated fibers. Current Biology, 17, R29-R35.

Hartline, D. K. (2008). What is myelin? Neuron Glia Biology, 4, 153-163.

Heath, T. A., Hedtke, S. M. \& Hillis, D. M. (2008). Taxon sampling and the accuracy of phylogenetic analyses. Journal of Systematics and Evolution, 46, 239-257.

Hedges, S. B. (2002). The origin and evolution of model organisms. Nature Reviews Genetics, $3,838$.

Lavrov, D. V. (2007). Key transitions in animal evolution: a mitochondrial DNA perspective. Integrative and Comparative Biology, 47, 734-743.

Liebeskind, B. J., Hans, A. H., Hillis, D. M. \& Harold, H. Z. (2017). Evolution of animal neural systems. Annual Review of Ecology, Evolution and Systematics, 48, 377-398.

Nakahara, J., Maeda, M., Aiso, S. \& Suzuki, N. (2012). Current concepts in multiple sclerosis: autoimmunity versus oligodendrogliopathy. Clinical Reviews in Allergy \& Immunology, 42, 26-34.

Nave, K. \& Werner, H. B. (2014). Myelination of the nervous system: mechanisms and functions. Annual Review of Cell and Developmental Biology, 30, 503-533.

Plazzi, F., Ferrucci, R. R. \& Passamonti, M. (2010). Phylogenetic representativeness: a new method for evaluating taxon sampling in evolutionary studies. BMC Bioinformatics, 11, 1-15.

Proctor, H. S., Carder, G. \& Cornish, A. R. (2013). Searching for animal sentience: a systematic review of the scientific literature. Animals, 3, 882-906. 
Schweigreiter, R., Roots, B. I., Bandtlow, C. E. \& Gould, R. M. (2006). Understanding myelination through studying its evolution. International Review of Neurobiology, 73, 219-273.

Smith, E. S. \& Lewin, G. R. (2009). Nociceptors: a phylogenetic view. Journal of Comparative Physiology A: Neuroethology, Sensory, Neural, and Behavioral Physiology, 195, 10891106.

Sneddon, L. U. (2017). Comparative physiology of nociception and pain. Physiology, 33, 6373.

Sneddon, L. U., Wolfenden, D. C. C., Leach, M. C., Valentim, A. M., Steenbergen, P. J., Bardine, N., Broom, D. M. \& Brown, C. (2018a). Fish sentience denial: muddying the waters. Animal Sentience 21(1).

Sneddon, L. U., Wolfenden, D. C. C., Leach, M. C., Valentim, A. M., Steenbergen, P. J., Bardine, N., Broom, D. M. \& Brown, C. (2018b). Ample evidence for fish sentience and pain. Animal Sentience 21(17).

Teles, M. (2016). No encalço da consciência animal: o problema epistemológico, a neurobiologia de Damásio e o comportamento animal. Revista Brasileira de Direito Animal, 11, 21.

Valentine, J. W. (2004). On the origin of phyla. University of Chicago Press.

Wilson, C. H. \& Hartline, D. K. (2011). Novel organization and development of copepod myelin. ii. nonglial origin. Journal of Comparative Neurology, 519, 3281-3305. 